\title{
Instructional Leadership in a Standards-Based Reform
}

Jonathan A. Supovitz

University of Pennsylvania, JONS@GSE.UPENN.EDU

Susan M. Poglinco

Follow this and additional works at: https://repository.upenn.edu/cpre_researchreports

Part of the Curriculum and Instruction Commons, Educational Administration and Supervision

Commons, Educational Assessment, Evaluation, and Research Commons, and the Educational

Leadership Commons

\section{Recommended Citation}

Supovitz, Jonathan A. and Poglinco, Susan M.. (2001). Instructional Leadership in a Standards-Based Reform. CPRE Research Reports.

Retrieved from https://repository.upenn.edu/cpre_researchreports/20

View on the CPRE website.

This paper is posted at ScholarlyCommons. https://repository.upenn.edu/cpre_researchreports/20

For more information, please contact repository@pobox.upenn.edu. 


\title{
Instructional Leadership in a Standards-Based Reform
}

\author{
Abstract \\ The spotlight of educational leadership is on instructional leadership. As pressure for improving student \\ performance in the current standards-based accountability environment swells and test results are \\ increasingly scrutinized, school principals are being urged to focus their efforts on the core business of \\ schooling-teaching and learning. But what does it mean to be an instructional leader? What do principals \\ that are instructional leaders do differently than other principals? How do they spend their time? How do \\ they shape the cultures of their schools? How knowledgeable are they of subject-matter content? How do \\ they work with, and develop, other leaders in their schools? In this study we sought to find answers to \\ these questions by exploring the collective wisdom of several effective instructional leaders. \\ Instructional leadership, not just by the principal but by a wider cast of individuals in both formal and \\ informal leadership roles, can play a central role in shifting the emphasis of school activity more directly \\ onto instructional improvements that lead to enhanced student learning and performance. By contrast, \\ the status quo in most schools is diffuse attention to instruction scattered amidst a variety of \\ environmental, social, and organizational distracters that lead to fragmented and uneven instructional \\ focus. Principals are typically engrossed in organizational care-taking and the responsibility for \\ instructional decisions falls to individual teachers. When individual teachers independently determine the \\ kind and type of instruction in their classrooms, three things tend to occur. First, the instructional culture \\ of the school tends to splinter, as there is no overriding instructional guidance and no coherent glue to tie \\ instruction to a larger whole. Second, the quality of instruction varies widely, as teachers bring different \\ experiences and have different notions of what is good teaching. Third, the content that students receive, \\ even in the same grade, differs from classroom to classroom, as each teacher prioritizes what students \\ ought to know.

\section{Disciplines} \\ Curriculum and Instruction | Educational Administration and Supervision | Educational Assessment, \\ Evaluation, and Research | Educational Leadership

\section{Comments} \\ View on the CPRE website.
}




\title{
Instructional Leadership in a Standards-based Reform
}

\author{
Jonathan A. Supovitz \\ Susan M. Poglinco
}

December 2001

(c) Copyright 2001 by the Consortium for Policy Research in Education 



\section{Contents}

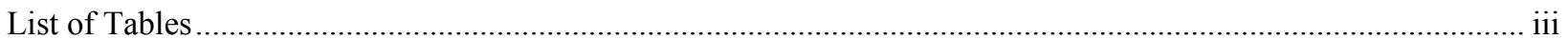

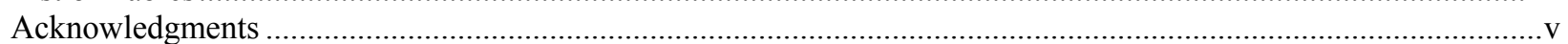

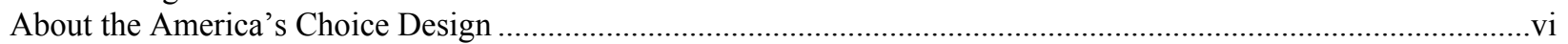

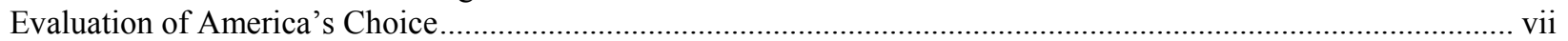

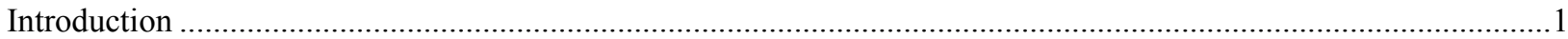

A Focus on Instructional Improvement Supported by a Vision of Instructional Quality .......................................

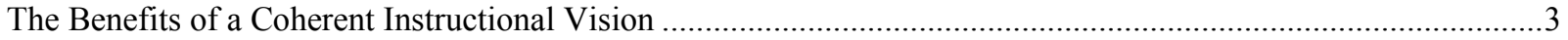

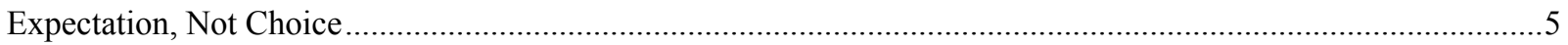

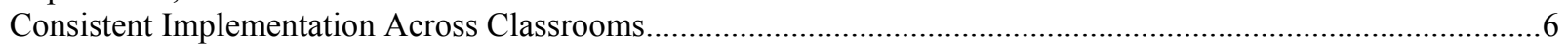

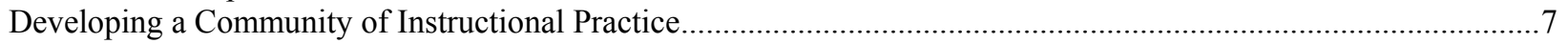

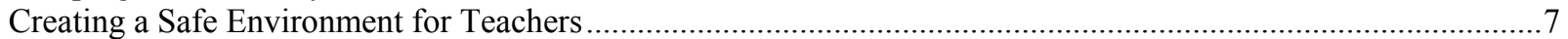

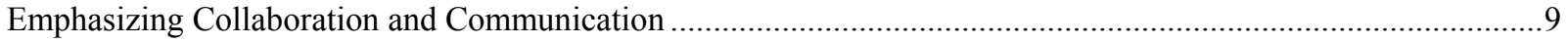

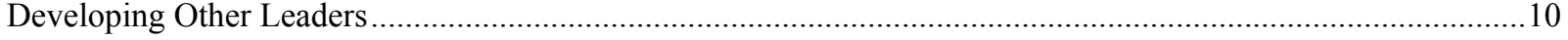

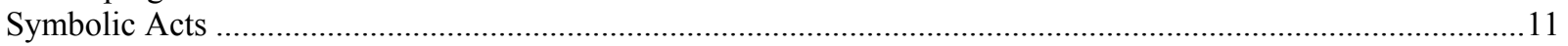

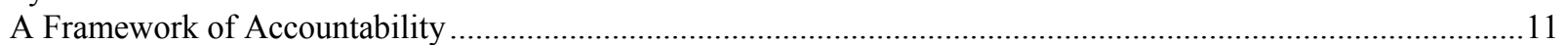

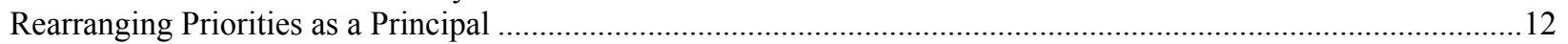

Observing Instruction and the Product of Instruction ............................................................................. 12

Developing Content Knowledge and Facilitating Teacher Content Knowledge ............................................14

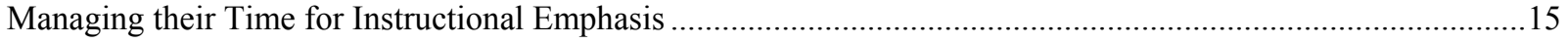

Becoming a Supporter and Service Provider to Teachers........................................................................ 16

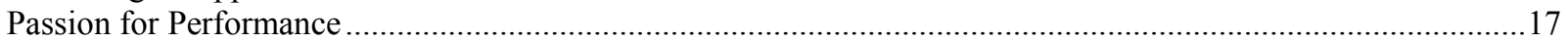

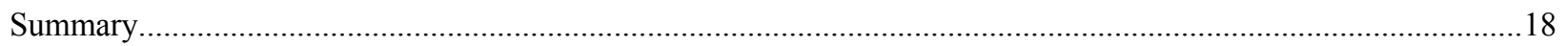

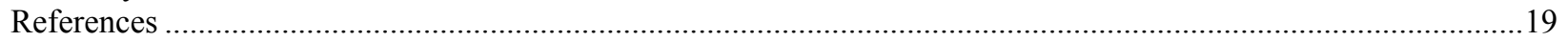

\section{List of Tables}

Table 1. Frequency that Principals Observe Instruction in Classrooms …...................................................13

Table 2. Subject-matter Content Knowledge and Importance of Subject-matter Content Knowledge of Elementary and Middle School America's Choice Principals 


\section{Acknowledgments}

The authors would like to deeply thank the following principals for collaborating on this report: Della Bryant, Yonkers, New York; Carolyn Calmes, Fresno, California; Carol Daniels, Jacksonville, Florida; Lillie Hubert, Hempstead, New York; Susan Kaufmann, Rochester, New York; Barbara Langley, Jacksonville, Florida; Audrey Murphy, Corona, New York; and Yvonne Noble, Los Angeles, California. Their valuable insights, wisdom, and stories were the bases for many of the details in this report. The analyses and conclusions reached, however, are the responsibilities of the authors alone. 


\section{About the America's Choice Design}

\section{7 he America's Choice School Design is a K-12 comprehensive school reform model designed by the National Center on Education and the} Economy. America's Choice focuses on raising academic achievement by providing a rigorous standards-based curriculum and safety net for all students. The goal of America's Choice is to make sure that all but the most severely handicapped students reach an internationally benchmarked standard of achievement in English language arts and mathematics by the time that they graduate.

America's Choice does not offer schools a script or a paint-by-numbers approach to reformed instruction. America's Choice recognizes that the pace of change will vary from school to school and the model does not have a rigid three-year implementation schedule. Rather, the core of the design contains a set of principles about the purpose of schooling and how schools should operate as well as a set of tools for building a program based on those principles. The essential principles and tools include:

- High expectations for student performance that specify what students should know and be able to do at certain educational junctures. These standards are explicitly expressed through the New Standards Performance Standards that provide a common set of expectations for students and teachers.

- An initial focus on literacy that features elements of phonics, oral language, shared books, guided and independent reading, daily writing, and independent writing.

- A common core curriculum that is aligned with the standards. Through the America's Choice literacy workshops, Core Assignments, and Foundations of Advanced Mathematics, school life is organized around a core curriculum.
- Standards-based assessments, including The New Standards Reference Examination, that are aligned with the standards and the core curriculum, and that provide detailed feedback to teachers and students about student skill levels in relation to standards.

- A distributed school leadership structure, led by the school's principal, that coordinates implementation, analyzes results and sets performance targets, implements safety net programs to provide time for students to receive additional instruction, ensures the necessary resources, and aligns schedules and other school activities with implementation of the design.

- Safety nets that are structured into the school day and year and that provide students with extensive support and multiple opportunities to achieve the standards.

- A commitment to teacher professionalism that enables teachers to function as full professionals by providing ongoing, on-site professional development and support that is aligned with the standards and in which content and pedagogy are intimately connected.

In order to become an America's Choice school, over 80 percent of a school faculty must indicate their commitment to the America's Choice design and agree to implement the program over three years. Each school must assign personnel as coaches to lead the implementation of the design, and a parent/community outreach coordinator who ensures that students get needed support services. 


\section{Evaluation of} America's Choice

$\mathrm{T}$ Economy (NCEE) to conduct the external
evaluation of the America's Choice School Design in 1998. Each year CPRE designs and conducts a series of targeted studies on the implementation and impacts of the America's Choice design. The report presented here is one of this year's evaluation reports.

The purpose of CPRE's evaluation is to provide formative feedback to NCEE and America's Choice schools about emerging trends in the implementation of the design, and to seek evidence of the impacts of the design using accepted high standards of evaluation design and analysis methodologies.

CPRE's evaluation of America's Choice is guided by three overarching evaluation questions about the implementation and impact of the design. First, is America's Choice being carried out in the manner envisioned - that is, how are teachers and school administrators understanding and implementing the many facets of the America's Choice reform design? Second, as a result of their implementation of America's Choice, are the instructional practices of teachers changing in ways that would improve student learning? Third, to what degree can improvements in student achievement be attributed to the design? Within this framework, annual evaluation studies target specific aspects of the America's Choice design for more indepth investigation.

To address these questions, the CPRE evaluation team gathers a broad array of qualitative and quantitative data to develop a rich and valid picture of the implementation process over time and to capture the impacts of the design on students and teachers. Our data sources include:
- Surveys of teachers and administrators in America's Choice schools nationwide.

- Site visits to schools across the country to observe classroom instruction, examine implementation artifacts, and interview teachers, students, and school administrators.

- Telephone interviews with NCEE staff, school faculty members, and school and district administrators.

- Document reviews.

- Observations of national, regional, and school-level professional development.

- Collection of a variety of student performance measures, including state and local tests, the New Standards Reference Examination, and more authentic samples of student work products.

After data collection, CPRE research team members analyze the data using appropriate qualitative and quantitative research techniques in order to identify patterns of intended and unintended consequences and to detect effects of the design on students, teachers, and schools. The results are reported in a series of thematic evaluation reports that are released each year.

To inquire about the evaluation reports that are available, please contact CPRE's communications office at cpre@gse.upenn.edu, visit our web site at www.cpre.org, or call us at 215-573-0700. 


\section{Introduction}

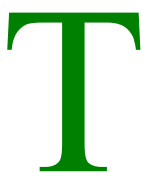

based accountability environment swells and test results are increasingly scrutinized, school principals are being urged to focus their efforts on the core business of schooling - teaching and learning. But what does it mean to be an instructional leader? What do principals that are instructional leaders do differently than other principals? How do they spend their time? How do they shape the cultures of their schools? How knowledgeable are they of subject-matter content? How do they work with, and develop, other leaders in their schools? In this study we sought to find answers to these questions by exploring the collective wisdom of several effective instructional leaders.

Instructional leadership, not just by the principal but by a wider cast of individuals in both formal and informal leadership roles, can play a central role in shifting the emphasis of school activity more directly onto instructional improvements that lead to enhanced student learning and performance. By contrast, the status quo in most schools is diffuse attention to instruction scattered amidst a variety of environmental, social, and organizational distracters that lead to fragmented and uneven instructional focus. Principals are typically engrossed in organizational care-taking and the responsibility for instructional decisions falls to individual teachers. When individual teachers independently determine the kind and type of instruction in their classrooms, three things tend to occur. First, the instructional culture of the school tends to splinter, as there is no overriding instructional guidance and no coherent glue to tie instruction to a larger whole. Second, the quality of instruction varies widely, as teachers bring different experiences and have different notions of what is good teaching. Third, the content that students receive, even in the same grade, differs from classroom to classroom, as each teacher prioritizes what students ought to know.
Instructional leadership, supported by the proper tools and resources, can counteract these tendencies toward fragmentation and incoherence. From extensive conversations with a group of principals identified as instructional leaders, three themes emerged as crucial elements of instructional leadership. First, instructional leaders organized their schools around an emphasis on instructional improvement supported by a distinct vision of instructional quality. Second, instructional leaders cultivated a community of instructional practice in their schools, creating safe and collaborative environments for teachers to engage in their work and drawing upon a wide network of individuals to deepen the work. Third, instructional leaders reorganized their own professional lives, time, and priorities to support instructional improvement. Through these three overarching strategies, instructional leaders shifted the priorities of their schools toward a more disciplined emphasis on improving student performance.

The data for this report come from principals implementing the America's Choice Comprehensive School Reform Design developed by the National Center for Education and the Economy (NCEE). America's Choice is a standards-based school reform model that focuses heavily on aligning standards, curriculum materials, assessments, and other student work products. This core is supported by a leadership and management structure that emphasizes organizational support for instructional improvement and by the building of instructional capacity through ongoing school-based professional development. At the time of the study (2000-2001), America's Choice was being implemented in approximately 200 schools nationally. Most of these schools, which had been implementing America's Choice for between one and three years, were elementary and middle schools. The design has since expanded to over 500 elementary, middle, and high schools.

Eight talented principals contributed their time, stories, and experiences from which this report is primarily constructed. In the Fall of 2000, America's Choice cluster leaders were asked to nominate principals who were effective 
instructional leaders of their schools. From the 20 America's Choice clusters of schools, 19 principals were nominated. From this group we randomly sampled nine principals and invited them to participate in the study. Participation involved two 90-120 minute interviews, one in the Fall of 2000, and the other in the Spring of 2001. One principal declined to participate and we continued with the other eight.

Of these eight principals, six led elementary schools and two were middle school principals. Their years of principal experience ranged from two to 17 years, averaging nine years. The schools ranged in size from 350 to 1,500 students. All schools were located in urban areas with high poverty levels, as measured by the percentage of students receiving free and reduced lunch assistance which ranged from 25 percent to 97 percent, averaging 60 percent. Minority students were the majority in almost all of these schools; four of the eight schools had overwhelming Hispanic student populations, three predominantly served African American students, while one was equally split between White and African American students.

Anecdotal stories of improved student engagement, understanding, and comprehension were plentiful. Principals freely shared stories of higher levels of student reading, writing, and mathematics, that they attributed to involvement in America's Choice and engagement in standards-based reform. About half of the schools had evidence of increased student performance as measured by improved student performance on state and district measures of achievement. For example, one elementary school in New York increased the percentage of fourth graders meeting the state standard in English language arts from 11 percent to 57 percent in two years. A middle school in Florida increased its grade on the state report card from a $\mathrm{C}$ to a $\mathrm{B}$. Other gains were more modest. The other middle school in the sample increased the percentage of seventh graders above the $50^{\text {th }}$ percentile on the SAT-9 from 23 to 30 percent.

Beyond the in-depth interviews with principals, two additional data sources contributed to this study. First, the Consortium for Policy Research in Education (CPRE) conducted a census survey in the Spring of 2001 of all 200 America's Choice principals as part of the annual evaluation of the design. The survey included questions about principals' content knowledge, the time they spent in classrooms, and what they did in classrooms. Of the 200 surveys that were administered, 139 principals responded, for a respectable response rate of 70 percent. Second, as part of fieldwork for the evaluation, 25 schools were randomly sampled for site visits and principals at each were interviewed. The protocol used was a slightly shortened version of the protocol used in the first round of interviews with the effective instructional leaders.

Before continuing, the reader should note two caveats about this work. First, this report does not attempt to exhaustively catalogue all of the components that compose instructional leadership. Surely there are important aspects of instructional leadership that are not touched on here. Rather, this is an attempt to illustrate some of the crucial qualities embodied in the strategies and techniques used by these instructionally effective principals. Second, the words of these instructional leaders are taken at face value. Many times, for other works, principals have described phenomenal acts of leadership and accomplishment and painted a robust picture of their schools, but in subsequent site visits and interviews with other members of their staff, it became apparent that others in these schools had distinctly different perceptions. In the absence of confirmatory evidence, which was outside of the scope of this study, we take the fact that these principals were nominated as high-performing instructional leaders to mean that they were truly doing what they purported to do.

\section{A Focus on Instructional Improvement Supported by a Vision of Instructional Quality}

Traditionally, school leadership has been a largely managerial job. In the book entitled, Managerial Imperative and the Practice of Leadership in Schools, educational historian Larry Cuban (1998) identified three dominant 
roles that have historically composed the jobs of educational leaders. First and foremost, educational leaders hold a managerial role as an administrative chief. Second, their jobs had a political role as a negotiator and facilitator with parents, administrators, and other constituencies. Third, they hold an instructional role as a teacher of teachers. Cuban argued convincingly that in most cases the managerial and political roles, not the instructional role, dominated the lives of most education leaders.

The life of a school principal thus can be seen largely as a tug of war among managerial, political, and instructional responsibilities. Typically, managerial duties overwhelm the other two roles and principals construct their roles largely as managers of their schools. Given these forces, the job of the instructional leader becomes an ongoing struggle to preserve a substantial proportion of time and energy for instructional supervision and to make their managerial and political responsibilities subservient to their instructional ones.

The principals that we interviewed recognized the sharp distinction between instructional leadership and management and prioritized instructional improvement responsibilities over managerial tasks. As they viewed it, managers focused on the operational aspects of the principalship, while instructional leaders emphasized the primacy of instruction through their actions. According to one principal, "The so-called traditional principal will stay mostly in his or her room, and do managerial-type jobs. They'll concentrate on maybe scheduling and programming and ordering supplies, and not getting out into the classroom and seeing where the instruction is."

The principals in our sample sought to focus their time and efforts on instructional improvement by shifting their priorities toward teaching and learning. As another principal explained:

Traditionally, principals have allowed themselves to get caught up in the operational minutiae. There's a broken pipe, there's a discipline problem. Paperwork and things that make us where we can't get out of the office. When you

make your primary focus instruction, you

have to spend a lot of time in...the classrooms.

Instructional leadership is not a substitute for management. Instructional leaders did not ignore the managerial aspects of their jobs, which all eight principals agreed were vital, but as instructional improvement became the primary emphasis of their organization, they refused to let it get crowded out.

"Management is still an important dimension of the principalship," explained one principal. "However, the instructional dimension is the key to total school reform. I am not minimizing management, someone has to make sure the trains run on time. However, if high-quality teaching is to occur in the building, the principal has to lead this effort." Instructional improvement became the organizing emphasis in the lives of these leaders, from which their decisions and priorities flowed.

Instruction improvement thus became the focus of school efforts in these schools and the foundation for all activities. But further, the instructional leaders used a variety of strategies to reinforce and distinguish their efforts. Chief amongst these were the articulation of a coherent vision of instruction, one which teachers and other faculty could envision and emulate; the development of a set of non-negotiable expectations for effort and practice; and consistent implementation of the vision across classrooms. In the following sections we describe these themes in greater detail.

\section{The Benefits of a Coherent Instructional Vision}

Powerful instructional leadership involves more than just a generic focus on instruction, although that is a start. Principals that increase their schools' focus on instruction will certainly improve their students' performance, for more instruction is surely better than less. But exponential value of instructional leadership comes from the marriage of an intense organizational focus on instructional 
improvement with a clear vision of instructional quality. A concrete vision of instructional quality provides a tangible representation of what effective instructional planning and delivery looks like, provides teachers with an instructional portrait they can work toward, and provides a picture that administrators can measure implementation against.

The America's Choice design provides instructional leaders with all of these elements. America's Choice provides leaders with a framework for instructional improvement based upon standards for the performance of all students, the continuous examination of student work, and consequent instructional activities. Second, the design provides a tangible vision of what effective instruction can look like. For example, the America's Choice literacy program contains a readers and writers workshop with a clear model of a mini-lesson derived from the needs of the group as evidenced in student work. This work is then contrasted against the standards. An independent or small group work period flows out of the mini-lesson and includes practice of particular elements of the craft of reading or writing. This is followed by a closure session which returns the class to the key elements of the mini-lesson and independent work period. Embedded within this structure are particular and purposeful embellishments, including the development of rituals and routines that minimize behavioral problems, the use of leveled texts that encourage student engagement, and purposeful teacher activities during the independent work period like conferencing with students, small-group guided reading, or modeling of independent reading or writing. Teachers and students use a variety of tools to develop and display the craft of reading and writing, including word walls, standardsbased bulletin boards, journals, source books, and portfolios. All of these elements of the America's Choice design are clear instructional activities that principals can readily see being implemented in the classroom.

The instructional leaders in our sample recognized the advantages inherent in both the standards-based philosophy of America's Choice as well as the well-developed instructional techniques promulgated by NCEE and the tangible vision of instruction that this produced. In their words:
I think because of America's Choice I
have moved into an arena where I do more instructional-type leadership before than when I considered myself as a school manager. Although I went into the classroom before...I didn't have a set script to use when I went into the classroom, I really didn't know what I was going in there for and what I was looking for. I saw things that I liked and I saw things that I didn't like. Now, I am able to say to teachers when I go into the classroom... 'Where are your word walls? How are students using the word walls? Let's talk about the book of the month?'...And I look more at what the children are doing than what the teachers are doing.

\section{I think the biggest difference is because I have a clear, focused vision of what this school needs to look like and what instruction needs to look like, and what children's work needs to look like. I have a clear charge.}

Before we started with America's Choice, I didn't have as good a vision or direction as I do now, but actually living it and breathing it, and through America's Choice I have learned so much. Going to the workshops, being part of a national cadre of administrators, sharing with them at the workshops, seeing fellow principals in other parts of the country and what they are doing. We all have the same goal of creating standards-based classrooms.

This concrete conception of instruction served two purposes for the savvy instructional leader. On the surface it provided them with a concrete vision of instruction against which to benchmark the instruction. But on a deeper level, this vision brought the serious and challenging work of instructional improvement to the forefront of the discussions and work. It changed the tenor of the work and helped principals to articulate a set of expectations. These expectations became the 
baseline for both academic and non-academic performance in the school. Teachers were not given a choice as to participation, but were expected to strive toward this vision in their daily work. Additionally, the principals expected this vision of instruction to be consistently applied across classrooms and over time. These expectations created a standard for instruction that, over time, changed the way that instruction occurred.

\section{Expectation, Not Choice}

Instructional leaders had a baseline expectation for all members of their school. The adoption model of these principals was not to create a vanguard of implementers and, through them, build a critical mass for change. Rather, they expected commitment across the entire school. As one principal explained, “...my expectation is that everybody is on the bandwagon. It may take some people longer, but my expectation is that everybody will be on that bandwagon. And I think that is the vision you need to have, you can't allow people to say well, I'm not going to do it and that's okay. Everybody needs to do it because that is the expectation here."

In essence, this meant suspending preconceived beliefs about differences and limitations of students. As another instructional leader put it, "I expect every single one of them to give this their all out effort, whether they're sure of it or not. In other words, to go in blindly and follow me and trust in the design and trust in me that this is good for kids."

Standards, both as a concrete set of goals for student knowledge and skills (as manifested in the New Standards Performance Standards) and as an abstract expression of uniform expectations for staff behavior and performance, provided an important framework and tool for instructional leaders. School leaders utilized this tool in a variety of ways. The New Standards Performance Standards became a concrete set of goals for the collective achievement of students and something that principals could expect to see classes working toward across the school. The idea of uniform standards for all, reinforced principals' notions of expectations for all teachers as well. Some schools carried the notion of standards into all aspects of school life. For example, in one school, the concept of standards permeated the school well beyond academics. There were posted standards for student behavior inside classrooms and standards for appropriate movement between classes. After a fire drill, the principal came on the loudspeaker to comment on class performance in meeting the school standards for the execution of an orderly fire drill.

Uniform expectations did not always sit well with all faculty members and interviewees mentioned several cases of recalcitrant teachers who refused to budge from their long-standing practices. These principals had very little tolerance for those who refused to try. They sought in many different ways to sway, disband, or dispel opponents to their efforts. For example, one principal communicated her expectations for commitment to the America's Choice vision before personnel were even transferred to the school. As she explained:
[The district] has a voluntary transfer program where teachers can transfer within schools and we get a list of people who want to come to our school, supposedly. One of my screening techniques is that I send out a cover letter that says, 'We are an America's Choice school and you are expected to do $X, Y$, and $Z$. If you still want to come and participate in those activities, then call for an interview.' And that screens out a lot of people who wouldn't work well here anyway.

Even in the face of changing external circumstances, these principals managed to maintain their commitment to their vision of instruction and the support needed to achieve it. One courageous story came from a principal in an urban district with a strong union presence:
The district used to have release days on Wednesdays and 30 hours beyond the school day for professional development. Well, both of those things went away in the new teacher contract. So my staff says, 'Well, with America's Choice which has all this professional development, 
what are you going to do now that we don't have to come?' And I stood up and said, 'No, you supposedly don't have to come, but you are a professional and we grow as learners and when I hold staff development I expect you to be there. If you can't be there you are still expected to implement whatever was going on in the staff development.'

The expectations of these principals pervaded the culture of these schools in a myriad of different ways, but the purpose of all these efforts was the same: to transmit a message to all that there was a purpose and a way of doing business and that it was the expectation of all faculty to enact this vision.

\section{Consistent Implementation Across Classrooms}

Another way that instructional leaders sought to make their vision of instruction the norm throughout their building was to develop instructional expectations for each classroom. Principals' expectations revolved around teachers' implementation of the America's Choice design. Instructional leaders expected consistency both across classrooms in their school and within classrooms over time. As principals explained:

Before I would have expected everyone to run a strong instructional program. Now what I expect is not only do they run a strong instructional program, but that the instructional program in every single classroom has the same elements, following the guidelines of standardsbased education, and using the standards as a guideline.

I spend up to an hour a day in classrooms. What I look for depends on the point for that day. If I go in during the beginning of writers workshop, I expect to see the mini-lesson going on. If I go in the middle, I expect to see some independent writing. If I go at the end, I expect to see the author's chair. And I expect it to happen consistently in each classroom.
If you don't monitor, it slips. So, for example, we did a focus walk a couple of weeks ago on writers workshop and there is one element of writers workshop where the teachers during independent writing are supposed to be writing themselves as a model, but there were some teachers who just weren't doing that. And so I asked them why they weren't doing that, and they said, 'Well, you know, I just want to get working with the kids.' And I said, 'No, we all need to be doing the same thing. They need to see you as the model describes,' and they said, 'Okay, we will go back to doing it.' So it is constant monitoring, holding the same high expectations for everyone.

The theme of consistency also manifested itself across the school schedule, where instructional leaders sought to protect the instructional schedule from a variety of intrusions.

Interruptions arise during the school year that tug at and tear time away from a regular instructional schedule. Band practice, pep rallies, athletic events, special assemblies, and intercom announcements are just some of the intrusions that tug and tear at the instructional routine of schools. Instructional leaders sought as best they could to protect their classrooms from these disruptions. As one principal voiced, "I don't take time out of the instructional day for anything, for any reason. We do it so the children have consistent instruction over a set period of time. Because if you keep changing the schedule, the kids lose it."

But these principals did not confuse consistency with conformity. Through their comments they demonstrated that they understood that teachers had a variety of valuable individual experiences, pedagogical techniques, and personality strengths. As one principal described, "It is just very important for me, personally, that I allow teachers to flex their creative muscles, but also to continue with the elements of the design. I want teachers to make this their own. I have to allow them to flex that creative muscle or tweak things to fit their style, but still maintain the integrity of the design." By mixing their own flavor into the design, teachers gained ownership over it; they made it their own. 


\section{Developing a Community of Instructional Practice}

A vision held solely by one person, no matter how powerful that vision, is invisible to others. In order for that vision to become reality, it must gain widespread acceptance and even advocacy throughout the organization. How does a particular vision of instructional improvement spread deeply throughout a school? How can a principal engender more than just compliance with superficial manifestations of her vision and encourage real consideration and adoption? One powerful approach is through the cultivation of a community committed to fostering instructional focus and improvement across the school.

The concept of communities of practice has been garnering support within education over the past decade. Based upon social learning theories (Lave and Wenger, 1991; Wenger, 1998), the basic idea behind communities of practice holds that groups that form around some specific purpose are a more effective means to achieve that purpose than would be individuals working on the same task in isolation. This is because there are synergies of learning in a social context that are believed to be stronger than traditional transmission methods. In order to develop effective group practices, the theory goes, individuals have to comfortably and regularly interact in order to form relationships in substantive and particular ways around specific activities. Thus, in education, school faculties or teacher teams that collaboratively engage in instructional focus are more likely to enhance student performance.

Developing meaningful communities around instructional practice is not an easy task. Groups may have a relatively easy time developing comfortable social interactions, but it is more difficult for them to develop sustained communities of practice around instruction. Recent research has shown that organizational restructuring alone does not increase the likelihood that groups will develop communities of instructional practice (Supovitz, 2001). Several barriers may impede the development of communities of instructional practice. First, conflicts may arise around traditional roles and responsibilities, between authority and autonomy. Second, philosophical disagreements about educational content and methods may arise. Third, the language of instructional refinement may not be held in common, leading to miscommunication. Fourth, incompatible incentive systems may send conflicting signals. Just because schools are ostensibly dedicated to teaching and learning does not mean that they can readily develop effective communities of instructional practice.

The schools represented by their principals in this study appear to have moved further along the road toward developing robust communities engaged in routines of instructional improvement. Our conversations with these leaders revealed several key ingredients in the development of these communities. In our interviews, instructional leaders discussed five strategies that they used to foster a community in their school that was focused on instructional improvement. First, these instructional leaders carefully developed a safe environment within which their teachers could take the risks associated with change. Second, they emphasized open channels of communication and strong collaboration amongst their faculty for the purpose of expanding the networks of engagement around issues of instructional improvement. Third, they cultivated informal and formal leaders in their schools to both allow themselves time for instructional attention and to broaden the base for change in the school. Fourth, instructional leaders employed powerful and symbolic actions and events to dramatize and reinforce their message. Finally, they developed strong systems for accountability even as they expanded teachers' flexibility to further develop their instructional practices.

\section{Creating a Safe Environment for Teachers}

Changing teachers' instructional habits means moving them from a place of comfort to a place of less security. Principals may employ a variety of strategies that require, request, and cajole teachers to risk moving away from their well- 
tried practices. Although the tactics of instructional leaders in our sample differed, they all fostered a safe environment within which teachers could more comfortably experiment with different forms of instruction advocated by America's Choice. As one instructional leader confided about her school, “...people feel that it is a safe environment and they have the freedom to fail knowing that it is not a life or death situation....and it is okay to think outside of the box." Another principal pointed out that there were no recriminations associated with changing one's teaching practices at her school: "... it is not an 'I got ya' atmosphere. It is an atmosphere of we all need to go to the same point, but each of us is in a little different learning curve, so we need different support along the way," she explained. "I provide to the best of my ability a risk-free environment, where my door is open, where teachers can come in and I welcome their ideas and their suggestions. I don't have a wall up that I am a principal or an administrator. I welcome their ideas... So I roll up my sleeves and I consider myself a learner along with them."

Providing safety for risk-taking behaviorcreating a safe environment for teachers to move away from their safe teaching zones - may seem paradoxical on the surface, and the principals we talked to tried in multiple ways to reinforce this message of security to take risks. For example, one principal sought to depersonalize the process of instructional change, to make it about the task, not the individual conducting the task. As she explained, "In meetings we have a lot of discussion about instruction, a lot of collaboration. And I reinforce that this is a safe time. This is a problem-solving time, it's about instruction, it's not about them."

Recognizing that there are disincentives to changing instructional practices associated with formal observations, many of the instructional leaders carefully separated their visits to classrooms for the purpose of nurturing teachers from the high-stakes routines embedded in their organizations. For example, several of the instructional leaders separated formal evaluative activities from their instructional improvement work with teachers. "When I visit classrooms it is not evaluative," explained one principal. "The teachers are developing a trust level and I am trying to develop that trust level with them that I am here to help." Most of the principals felt that formal evaluations, because of the stakes attached to them, made teachers less likely to use instructional approaches that they were less comfortable with. They therefore sought to cordon off official observations from their everyday instructional development work.

Open adult learning in schools violates longheld stereotypes of teachers' professional expertise. The expectations of our educational culture are that teachers - as if somehow by virtue of their titles as 'teachers' - are experts of their craft. Even new teachers are illogically expected to be masters of their profession, springing forth from their pre-service experiences like modern-day Athena's, fully equipped to lead our youth to high levels of knowledge and skill. The scarce opportunities and time available for professional development in most school environments is a testament to the low priority that we place on teacher learning. Teachers are supposedly 'the learned.' But truly effective teaching (as opposed to caretaking) is a lifelong challenge in itself, a multifaceted endeavor, filled with complex student-teacher and student-student interactions and instant opportunities grasped and missed. Developing this intricate craft takes ongoing training, experience, and reflection.

The principals in our sample were intimately familiar with the challenges and complexities of teaching and sought to create and reinforce the notion that their schools were learning environments for teachers as well as students. The theme of a learning environment wended its way through many of our conversations with principals about their conceptions of instructional leadership. As one principal confided:

An instructional leader has to be, I would say, willing to be a learner, a lifelong learner, to acknowledge that you don't know everything, that you're not the beall knows-all, that you're learning alongside with your teachers. And that you're willing to share with them in their learning. And you need to learn to take a 
chance and try something. And teachers need to know that if they try something and it doesn't work, that it's okay, that they are not going to get written up or reprimanded.

Another principal similarly talked about her school as a safe learning environment for teachers:

I am a great believer in conversations with people. You've got to talk to them and listen to what they have to say, and offer the opportunity and frame it in such a way that people understand that it is okay if something happens, because we can fix it. We are in this together and we'll learn together...And if you are open to ideas, individuals are more likely to step forward and accept the challenge.

These principals fostered both a sense of security in their schools and an environment that valued the exploration and improvement of the craft of teaching that encouraged teachers to push their instructional skills forward and to feel comfortable taking the personal risk to experiment with practices.

\section{Emphasizing Collaboration and Communication}

Collaboration and communication were also repeated themes in instructional leaders' strategies for kneading the America's Choice design into the everyday workings of their schools. The instructional leaders saw collaboration and communication not as ends in themselves, but as important processes for spreading a culture of instructional improvement throughout their schools. Collaboration gave faculties a sense of involvement and ownership in what they were doing and built a commitment to the design. Collaboration and constant communication became an opportunity for faculty with different levels of understanding of the design to learn from each other.

Collaboration was also a basis for instructional leaders to build widespread staff support for instructional improvement. For example, one principal used collaboration as a leadership tool to gain buy-in from her staff. "It's all around collaboration," she explained. "It's all around the leadership of where you are going in that collaboration. Especially with the America's Choice model, they will talk to me about what is the main issue that makes or breaks it, and I will say without hesitation that it is collaboration... You have got to have staff that has bought into doing that and working with you, and I've got an incredible staff here."

Many leaders described collaboration in their school as a sense of shared learning. The act of learning together, a key activity in the development of a learning community, banded the principal and faculty together in pursuit of increasingly effective instructional approaches and support systems that brought about higher levels of student achievement. "I think that I gained a lot of trust from letting them know that I am in this learning process along with them to really problem solve what it takes to improve student performance," said one principal. "So I think it is a message that we are really looking at this together and I am not going to ask them to do anything I wouldn't do."

Most of the instructional leaders also stressed the need for frequent and ongoing conversations with teachers and other administrators. As one put it, "I am a great believer in conversations with people. You've got to talk to them and listen to what they have to say, and offer the opportunity and frame it in such a way that people understand that it is okay if something happens, because we can fix it. We are in this together and we'll learn together...And if you are open to ideas, individuals are more likely to step forward and accept the challenge."

The purpose of communication was to empower staff to take ownership of their work. "I want there to be that open door communication with all my staff," explained one principal. "To not be afraid-you know: 'Oh, the principal's office.' That my door is open and that they can approach me about anything. I want them to join me and I told them this from the beginning. I want them to join me in creating the climate for the school. We're creating policy here, we're creating our movement forward. If they have 
any ideas that they think will work, I welcome them." Many of the principals spent a lot of time in conversation with staff.

Another purpose of ample collaboration and communication was to provide opportunities to identify and develop expertise across the building. Principals that sought to expand the instructional quality and capacity of their staffs recognized that collaboration and communication were mechanisms to share and build expertise among their faculty members. As one principal observed, "Part of being an instructional leader is that you don't do everything. You work with your staff so that they are the experts, and they are collaborating. And you come together with them in that collaboration of their knowledge and your knowledge together." Collaboration and communication were strategies for expanding and solidifying instructional emphasis.

\section{Developing Other Leaders}

Spillane, Halverson, and Diamond (2001) argue that it is more legitimate to examine school leadership as the cumulative activities of a broader set of leaders, both formal and informal, within a school rather than as the work of one actor. The principals in our study were quick to attribute their work to a broad leadership base in their schools. As one principal in our study told us, "I no longer labor under self-imposed omniscience. There are many staff with professional expertise to move the effort forward." Principals may be "leaders amongst leaders,' but it serves both their own and their schools' interests to develop a broad set of leadership in their schools. The development of other school leaders serves many purposes. First, it expands expertise across the faculty, thereby deepening efforts for instructional improvement and increasing the likelihood that these efforts will be sustained over time. Second, it became a necessity for principals to lighten their management burden in order to spend more time in the classroom and on instructional issues.

We found that the principals in our study relied on the leadership structures of the America's Choice design to assist them in decision-making. According to one principal, "Teamwork is a very important driving force here. I don't view myself as the 'see it all, know it all, do it all' principal. I have a committee, my school leadership team is a committee. We hire teachers through the committee, consider school-based options. I welcome their input, and I accept their judgment. I call them in to look and evaluate things with me. Everything we have done in this school I believe we have done together as a school effort." A broader set of individuals in the school were involved in decisions that impacted them, strengthening the base or collective responsibility.

When high-quality instruction becomes the central effort of a school, then those that are quality instructors become increasingly valued. Many of the leaders that arose in schools that had developed communities of instructional practice did not hold formal leadership positions in the school. Yet, since the prime focus of these schools was instructional improvement, and the currency in these realms was instructional expertise, it is not surprising that the principals turned to effective teachers to become leaders in the schools. As one principal said, "I give people challenges, pushing them to the next step. And those that figure these things out become leaders. They adapt it to their instructional needs and create working products of this in their classroom and then they become a leader because they have discovered something to share..."

In another school the increased emphasis on instruction brought forth by America's Choice resulted in a more inclusive notion of school leadership. According to the principal, "I now have identified my sleepers. Individuals that you would not have considered, for whatever reason, and they are emerging as leaders. It is almost as if they were waiting for a design that would provide them with a framework that is so encompassing, that they could step forward. But for whatever reason they were not formally leaders." The hierarchy of value had changed in these schools. Once the principals gave value to instructional quality, effective instructors became more valuable.

Distributing leadership responsibilities across the staff of a school is a necessity for principals 
who want to protect a portion of their time for instructional leadership. Many of the principals we talked to made a conscious effort to spread their management responsibilities across formal school leader positions. However, these principals were also cognizant that they couldn't just shift their management responsibilities to their assistant principals, who also needed regular classroom exposure and instructional experiences in order to participate in the conversations about instruction that contributed to the decisions and guided the direction of the school. One principal explained that she shared budgetary responsibilities with one of her vice principals, but "I also want my vice principals working with kids. I want them in the classroom. So when they are working with our leadership team they have an understanding of what is going on."

\section{Symbolic Acts}

Statements or acts that shake up a school's faculty can unshackle them from deeply ingrained ways of doing business and help them to see possibilities that were unimaginable before. Several of the principals we talked with employed symbolic acts or statements to reinforce their visions of instructional focus. For example, one principal came into her school with what appeared to be a wildly ambitious goal. "I told them three years ago when I came in, and they all thought I was crazy. I said I want to be one of the few schools that are highpoverty schools that succeed. I wanted to be a 90-90 school, with 90 percent of the students below the poverty level, but 90 percent of them meeting the standards. And I told them that is where we are going and I keep repeating it." Test results from 2001 showed that the school had just under 60 percent of the students reaching standard, an improvement from about 10 percent when they started. The concrete performance goal of this principal, stated repeatedly, gave this faculty a sense of expectation.

Another marvelous story told to us by a principal that was nominated as one of the highperforming instructional leaders but not part of our sample of interviewees, carried an age-old message. In the first year of its implementation of America's Choice, a school leadership team had developed a checklist for implementation of standards-based reform in each classroom.

Teachers used the checklist to confirm that they were implementing various pieces of the model. But at the end of the first year the principal became concerned that the 'checklist mentality' was impeding a deeper implementation of the design. So the principal held a wake, replete with candles and black crepe paper, to end the use of the checklists. At the center of the wake, in a small cardboard coffin, stood a paper shredder. Solemnly, the teachers filed in and passed their checklists through the paper shredder into the great beyond. Symbolically, this principal was sending the message to her faculty that the checklists had served their purpose, but it was time for them to move beyond, to a deeper level of implementation.

\section{A Framework of Accountability}

A culture of accountability provided an important impetus for participation in the communities that principals sought to develop. While the context for improvement was based upon a nurturing environment, with attendant emphasis on safety, collaboration, and plentiful communication, a framework of accountability provided an important motivation and expectation for participation.

The principals were all experienced educators, either as teachers, administrators, or both and they recognized that their faculties were composed of adults with a myriad of motivations. Accountability for performance became a major mechanism for these principals to promote adoption of the design in their schools. As one principal explained:

Initially I had to monitor it much more than I do now. Because of human nature, because some people are going to do it because it is the right thing to do, some people are going to do it because they need their peer encouragement, and then some people are going to do it because they don't want to get caught. Whoever 
you are, we are still going to monitor this to make sure it happens.

Principals applied incentives and disincentives to their systems in many small but telling ways. Principals publicly acknowledged teachers that were successfully adopting the America's Choice design as leaders for their grade levels. Teachers that refused to adopt standards-based practices were asked to teach at other schools. As one principal put it, "So, if you're here, you're here because you chose to be here, so let's implement the design. And if you chose not to implement the design, then it is your responsibility to leave." Resources, support, and attention were focused on those who put their efforts into implementing the design. "We put out expectations and we expect people to do their job and then we follow up on it," said one principal.

Several of the principals viewed their accountability systems as a tacit agreement with teachers: you will have all the support you need to do this work and you will be expected to do it. As one principal framed it: "You have to have a philosophy that everyone in the classroom teaching is not a servant of the instructional process. So we do everything within our power to give teachers the opportunity to do what they need and hold them accountable for doing it."

It is, no doubt, challenging to develop a coherent set of expectations and incentives within a school. But once the contours of a community become well established, appropriate and inappropriate forms of behavior become almost self-evident and self-policing. In many cases, the invisible pressures of the community itself provided a powerful force of collective responsibility that pushed participants toward conformity and ostracized those that rebelled. Thus, over time, the principals themselves became less important enforcers as the community itself held its members accountable.

Finally, it must be noted that, while principals were able, to a great extent, to construct the communities with their schools, a variety of external forces impinged upon these systems. Programs imposed by districts, state testing programs, and even federal requirements sent contradictory and confusing signals of priorities into schools, providing competing incentives for teachers.

\section{Rearranging Priorities as a Principal}

Preserving time for instructional leadership means that principals have hard choices to make about their time and priorities. Considering the conflicting demands of daily events, it is understandably difficult for school leaders to be proactive, rather than reactive to the constant 'crisis' situations that seemingly arise on an hourly basis. Four themes emerged from our discussions with principals that show how they rearranged their priorities to reinforce their emphasis on academic performance and instructional improvement. First, instructional leaders spent more time in classrooms looking at instruction and the product of instruction. Second, instructional leaders more effectively managed their time around instruction. Third, even as they developed their own content knowledge, they recognized their primary role as facilitators of the acquisition of content and pedagogical content knowledge of their teachers. Finally, as they recognized that instruction was the primary means for improved achievement, they re-conceptualized their roles as service providers to teachers.

\section{Observing Instruction and the Product of Instruction}

Instructional leaders spend a lot of time in classrooms. As one principal explained, "When you make your primary focus instruction, you have to spend a lot of time in the place where instruction is going on, and that's in the classrooms." Results from CPRE's survey show that the principals identified as instructional leaders spent substantially more time in classrooms than did other America's Choice school principals. Table 1 shows the responses of principals to a survey item asking them how frequently they observed instruction in classrooms. For all America's Choice principals, 39 percent observed instruction daily or almost 
Table 1. Frequency that Principals Observe Instruction in Classrooms

\begin{tabular}{lcc}
\hline & $\begin{array}{c}\text { All America's } \\
\text { Choice Principals } \\
(\mathrm{n}=127)\end{array}$ & $\begin{array}{c}\text { Principals Identified as } \\
\text { Instructional Leaders } \\
(\mathrm{n}=17)\end{array}$ \\
\hline Daily or Almost Daily & $39 \%$ & $88 \%$ \\
Once or Twice a Week & 50 & 12 \\
Once or Twice a Month & 9 & 0 \\
A Few Times a Year & 2 & 0 \\
\hline
\end{tabular}

daily, 50 percent observed instruction just once or twice a week, and 14 of the America's Choice principals (11 percent) only bothered to go into classrooms once or twice a month or less.

By contrast, the principals that were identified as instructional leaders observed instruction in classrooms far more frequently. Of the 17 principals responding to the survey that were nominated as instructionally-focused principals by their cluster leader, 15 , or 88 percent, observed instruction daily, while only two, or 12 percent, observed instruction weekly; thus showing that instructional leaders spend a lot of time in classrooms.

Although instructional leaders spend more time in classrooms than other principals, what is even more important is what they do when they are inside classrooms. The consensus among the instructional leaders was that they focused more on talking with students and examining students' work than they did on teachers' behaviors:

I focus on the student while in the classroom, not the teacher. I talk with students about their work. Does it meet the standard? Why? Why not? What do they do if they need help reaching the standard?

I am looking for student work that meets standards. I am looking to see that the students understand how standards drive their work. That they are independent learners so that they know that their work is dependent on the effort they put into it, not just because their teacher told them to do it.

[I am] talking with the children about their work and their reading, and listening for cues from the children that indicate that they understand the work that they're doing and how it relates to the standards, and how it is evaluated, that they can go back and revise, when necessary.

I am looking for depth. I think so many times in education we are mesmerized by form over substance. I am looking for substance. In writing, for example, I want to see writing over time. I want to see writing that meets the standard. I want to see attention to conventions. I want to see evidence that the child is becoming an independent learner.

Student explanations and student work are evidence of student performance-both outcomes of the educational process. By targeting student skills and abilities as the focus of their classroom attentions, these principals are attending to the outcomes of the work of educators rather than only looking at teachers' instructional methods. The comments of these principals also demonstrated that they were very knowledgeable about the levels of depth of student understanding exemplified by America's Choice as well as the process of relating student work to standards as a means of gauging effective instruction. Thus, the focus on student work as the product of instruction was of 
primary importance to these principals. Based upon these data, principals then turned to assisting teachers.

\section{Developing Content Knowledge and Facilitating Teacher Content Knowledge}

When substantive subject-matter knowledge increasingly becomes a concern for principals who seek to spend more time on instruction, principals grapple with their instructional responsibilities; they assess their knowledge of the major content areas against what they perceive as necessary content knowledge to do their jobs well. As principals across the America's Choice design began to focus on instruction, they did this mental calculation and many found their content knowledge wanting.

Both elementary and middle school America's Choice principals felt it was very important to have more contextual knowledge. Table 2 shows the responses of elementary and middle school principals about their content knowledge in each of five major subjects and their beliefs in the importance of principals having a great deal of content knowledge in these subject areas. Looking at the first four columns, about 60 percent of elementary principals reported a great deal of content knowledge in reading and writing, with fewer reporting a great deal of content knowledge in mathematics and social studies. By contrast, a smaller percentage of middle school principals reported a great deal of

Table 2. Subject-matter Content Knowledge and Importance of Subject-matter Content Knowledge of Elementary and Middle School America's Choice Principals*

\begin{tabular}{|c|c|c|c|c|c|c|}
\hline \multirow[b]{2}{*}{ Content Area } & \multicolumn{3}{|c|}{$\begin{array}{l}\text { Extent of Principals' } \\
\text { Content Knowledge }\end{array}$} & \multicolumn{3}{|c|}{$\begin{array}{l}\text { Importance of Having a Great Deal } \\
\text { of Content Knowledge }\end{array}$} \\
\hline & $\begin{array}{l}\text { None or } \\
\text { Little }\end{array}$ & Some & $\begin{array}{l}\text { A Great } \\
\text { Deal }\end{array}$ & $\begin{array}{l}\text { Somewhat } \\
\text { Important }\end{array}$ & $\begin{array}{c}\text { Fairly } \\
\text { Important }\end{array}$ & Very Importan \\
\hline \multicolumn{7}{|c|}{ Elementary $(n=110)$} \\
\hline Reading & $6 \%$ & $35 \%$ & $60 \%$ & $3 \%$ & $11 \%$ & $86 \%$ \\
\hline Writing & 4 & 41 & 56 & 3 & 13 & 85 \\
\hline Mathematics & 7 & 56 & 37 & 5 & 27 & 68 \\
\hline Social Studies & 15 & 56 & 30 & 18 & 44 & 38 \\
\hline Science & 29 & 57 & 14 & 17 & 42 & 41 \\
\hline \multicolumn{7}{|l|}{ Middle ( $n=22)$} \\
\hline Reading & $18 \%$ & $55 \%$ & $27 \%$ & $9 \%$ & $18 \%$ & $73 \%$ \\
\hline Writing & 14 & 46 & 41 & 9 & 23 & 68 \\
\hline Mathematics & 23 & 41 & 36 & 18 & 41 & 41 \\
\hline Social Studies & 9 & 55 & 36 & 23 & 50 & 27 \\
\hline Science & 27 & 64 & 9 & 27 & 36 & 36 \\
\hline
\end{tabular}

* Percentages may not add to 100 due to rounding. 
content knowledge in almost every subject. Writing, mathematics, and social studies were the subjects that principals reported to be most knowledgeable about, although only four in 10 reported a great deal of knowledge in any of these subjects.

Principals felt they needed to have more content expertise. Around 85 percent of elementary principals viewed a great deal of content knowledge in reading and writing, and to a lesser extent mathematics, as very important. Middle school principals were slightly less vociferous, but seven of 10 still viewed a great deal of content knowledge in reading and writing to be very important. Thus, the pattern across these data is strikingly clear. In virtually all cases, across subjects and grade levels, principals felt it was very important to have more content knowledge than they felt they had.

The extent of content knowledge required of an instructional leader was also a prickly issue. All the principals agreed that they needed a sophisticated knowledge of content areas, particularly literacy, in order to intelligently guide teachers toward honing their instructional skills. As one principal put it, "The instructional leader has to be up-to-date on instruction. What's new, what's current. And be able to convey that to the staff, and actually believe it."

But principals diverged on the extent of content knowledge required to effectively do their jobs. Some principals argued that they needed to be experts in all the content areas. One principal, for example, said, "I think you have to have the knowledge of all the content areas, and what is needed for each grade level and what is needed according to the standards. For example, I don't know how you could be a good instructional leader if you didn't understand literacy and how a child learns to read and write." Another principal concurred, "I think you need one hundred percent. I think ELA content knowledge is very, very important. You have to know the curriculum of all the subjects and grade levels."

But high levels of content knowledge in each of the instructional domains appears to be a trap for all but the most extraordinary principals. Particularly in the middle and upper grades, it would seem to be impossible for any individual to master the details of the content areas. The two middle school principals in our sample were particularly aware of the limitations of their content expertise across subjects. As one put it, "A leader vests in certain people in certain areas of expertise. I have a working knowledge of what is going on and I meet with them regularly so that my working knowledge is expanded...I make sure the staff knows that they are really the experts in their particular areas, my knowledge is general."

A subset of the instructional leaders we interviewed sought to develop their content knowledge, while recognizing their primary responsibility as a facilitator of the acquisition of content knowledge for other teachers. They viewed their role less as content area experts, and more as facilitators of teachers' acquisition of additional content knowledge. As one principal put it, "You've got to have a lot of content knowledge. But more than even content knowledge, you've got to have an understanding that you are a continual leader of learning and professional development...So it is not only content knowledge, but it is knowing the processes of learning, it is understanding what types of teaching strategies you need to work with." Another principal commented similarly, "I don't think any one content area is paramount. What you need is process. But if there is any area where you need content knowledge, it's English because you're asking people to use strategies across the curriculum to deal with literacy." Still a third said, "You have to have a knowledge of instruction and you have to have a knowledge of how to guide instruction along using the standards." These principals recognized that they were not the primary trainers of their teachers, and therefore, while they needed the expertise to discern quality instruction, they were primarily brokers and facilitators of professional development experiences of their staff.

\section{Managing their Time for Instructional Emphasis}

Time is the bane of any busy professional, but for instructional leaders it poses a particular 
challenge because they seek to spend substantial time in classrooms and instruction is only occurring for part of the day. The principals were careful to manage their time so that first, they signaled to faculty and parents that instruction was the priority of their school and second, they were able to spend a reasonable chunk of their time in classrooms. They viewed their jobs much like a sandwich, with administrative and political tasks surrounding the instructional meat of their days.

These principals, like most, worked hard, toiling for long hours at their jobs. Many commented how they came early and stayed late. "I arrive early in the morning to do the managerial things that have to be done or do them after school, so that during the day I have plenty of time to talk with teachers," explained one principal. "I spend a lot of time in classrooms, so that I can see the actual work that students are doing," she said. Another reiterated this theme. "But the day-to-day running of the school, a lot of it is managerial, in terms of safety issues, in terms of parent demands, in terms of deadlines, in terms of paper demands. And what I find myself doing is staying late and taking care of the paper demands at home or after school," she said. "I save all my paperwork and every night I go home with a big folder of all my mail," said another.

Several of the principals stressed how they reallocated their time by scheduling meetings with parents and others outside the building either before or after school. "I try not to have paperwork to do during the time that I am supposed to be a leader," explained one principal. "...My day is spent mostly with the students and with staff and faculty...my schedule for meeting with parents is before 9:15 and I don't meet with parents again until the next day because I am with my students... So I have tried to schedule myself so that my students and my staff have my sole attention during the time they are here..." Other tasks came before or after this protected time.

The old adage says that work fills available time. It is surprising to find that tasks that are constrained to smaller blocks of time and lower priority still get done. As one principal told us, "I don't languish over the fact that I've got to get a maintenance report in. I think many times principals spend a lot of time worrying about things they can't do anything about instead of worrying about something they can do something about. So I don't schedule a lot of time there. And it works. It is amazing how when you keep first things first, everything else falls into line. And the instructional piece is first."

The principals also talked about streamlining their workload by making hard choices to discard lesser priorities. "I have just about turned facilities over to an assistant principal. I don't deal with tests. I don't deal with facilities, it's something that we talk about and they debrief me...So, some of the other management pieces, they have been strategically abandoned."

\section{Becoming a Supporter and Service Provider to Teachers}

Instructional leaders take every opportunity to support teachers in their work and enhance teachers' skills to improve student learning. Principals' support for teachers manifested itself in a variety of ways including encouragement, counseling, and as a resource provider. Taken together, these efforts subtly changed the emphases of principals' roles into that of a service provider of the work of teachers.

Principal support for teachers manifested itself in a variety of ways that appeared to be dependent on the personality and temperament of the principal, the particular needs of individual teachers, and the environment of the school. One principal, for example, provided support to teachers on an individual basis. She explained:

I think that the instructional leader has a responsibility to meet and talk to the teachers on a regular basis about 'Are you satisfied with the job you are doing? What can I do to help you do your job better?' And whatever that person says, if it's related to classroom instruction, I need to try and do it. The instructional 
leader always lets the teachers know that it is my job to facilitate what you need to be doing. Even if it is something insignificant or small, like 'I would like to have a white board in my room.' Then I go and get it, because that has a big impact.

Another principal saw herself as a source of encouragement and support for her teachers. As she described, "What we do is, teachers who are getting up and doing the model in their classroom, the America's Choice model, we commend them, congratulate them, support them, whatever they need to make it work." Others saw themselves as protectors, "I must provide strong support to teachers, especially those who have standards-based classrooms. Often I must protect them. I must lead the effort to keep the focus on student work, constantly monitoring it, analyzing it against the standards."

Another principal saw herself as a counselor for teachers, nurturing them through the uncertainties of the change process:

As the training began and the implementation of the strategies began, there was a lot of paradigm shifting going on and a lot of teachers that thought they were good teachers started doubting themselves. And so I had conversations with many of them and their comment was, 'I thought I was a good teacher, and now I'm having to change and I thought I knew what I was doing.' And so I was in a counseling mode and I was saying things to them like, 'You are a good teacher, you're just learning more strategies and tools to help you become an even better teacher.' Morale hit an all-time low in our first year in November. It was a lot of stress. And then, in the following couple of months, we started to see the results of our efforts in our children's work. And when we started to see the level of writing these kids were exhibiting, it became a whole different ballgame. And everybody was thrilled and very, very pleased.
Through a variety of ways, instructional leaders redefined a part of their jobs to be supporters of the work of their teachers. No longer can the work of the principal be distinct from that of teachers. Instead, principals' roles become symbiotic with those of teachers. Instructional leadership binds principals more closely to teachers and to the everyday activities of classrooms.

\section{Passion for Performance}

This story would not be complete without mention of the personal dedication of the principals involved in this study. Principals come in all shapes, sizes, and colors. Some are voluble and some are restrained. Some lead from the front and others shepherd from the pack. Some are cheerleaders and others are silent observers. But one set of qualities that consistently stood out from the instructional leaders we interviewed was their passion for improving student performance, their faith in their efforts, and their commitment to their work. Their words convey their passion with eloquence:

It can't be something rote. The message can't be given out to the staff that this is something temporary that will be going away, that this is a new fad, the new thing and we'll pretend we're doing it and we'll look the other way 'til it passes. This is something that principals, as leaders, have to believe, have to live, sleep, and breathe.

...I have a clear, focused vision of what this school needs to look like and what instruction needs to look like, and what children's work needs to look like. I have a clear charge. I kind of feel like a bull in a stampede, you know that one that they do in Mexico [sic] with all these people that are stupid enough to get in the way? Well, I am one of those bulls and I am at the head, at the front, and I am pushing every single obstacle out of my way. No matter what it takes, I am doing it. If it means that I have to stretch the rules, stretch the policy, or not tell everybody what I am doing, then that is what I am 
going to do. And in the past, while I had good ideas about what instruction should look like, I didn't quite have the fever that I have now about it. Passion seems to be an overused word these days, but that is what it is.

\section{Summary}

Every week school principals make hundreds of choices, big and small. Whether by plan or caprice, these decisions together weave the cultural tapestry that defines the customs, priorities, and way of life at a school. Instructional leadership is a guiding principle, a compass, to help direct principals and other leaders in their decision-making. The ideas and strategies expressed in this report provide insight into the way that a small group of instructionally effective school leaders organized their schools and personal priorities to pursue improved student performance. By developing an organizational emphasis on instructional improvement, promoting a distinct and unifying vision of instructional quality, creating a community in support for their vision, and restructuring their own priorities, these principals demonstrate how schools can attain the instructional emphasis that leads to notable improvement in student performance. 


\section{References}

Cuban, L. (1988). Managerial imperative and the practice of leadership in schools. Albany: State University of New York Press.

Lave, J., and Wenger, E. (1991). Situated learning: Legitimate peripheral participation. Cambridge, England: Cambridge University Press.

Spillane, J. P., Halverson, R., and Diamond, J. B. (2001). Investigating school leadership practice: A distributed perspective. Educational Researcher, 30(3), 23-28.

Supovitz, J. A. (2001). Developing communities of instructional practice. Philadelphia: University of Pennsylvania, Graduate School of Education, Consortium for Policy Research in Education.

Wenger, E. (1998). Communities of practice: Learning, meaning, and identity. Cambridge, England: Cambridge University Press. 
